\title{
Correlations between Topological Ring-Currents, $\pi$-Electron Partitions, and Six-Centre Delocalisation Indices in Benzenoid Hydrocarbons
}

\author{
Alexandru T. Balaban ${ }^{a}$ and Roger B. Mallion ${ }^{\mathrm{b}, *}$ \\ ${ }^{a}$ Texas A\&M University at Galveston, 5007 Avenue U, Galveston, Texas 77551, \\ United States of America \\ ${ }^{\mathrm{b}}$ School of Physical Sciences, University of Kent, Canterbury CT2 7NH, \\ England, United Kingdom
}

RECEIVED JANUARY 17, 2011; REVISED JUNE 25, 2011; ACCEPTED JULY 14, 2011

\begin{abstract}
Comparison is made between three different indices that characterise the individual rings of a wide range of condensed benzenoid hydrocarbons. Two of these (" $\pi$-electron partitions" and the six-centre delocalisation-indices that have been called " $\Delta_{6}$-values") have been introduced only recently as potential indicators of what might be called "local aromaticity", whilst the third ("topological $\pi$-electron ringcurrents") was suggested as a possible discriminator in this regard nearly fifty years ago. Whilst linear correlations between ring currents and $\pi$-electron partitions within certain restricted classes of ring types are good (with correlation coefficients of up to 0.998), agreement between the two indices over all classes of ring types is poor. Predictions arising from a consideration of $\pi$-electron partitions and $\Delta_{6}$-values seem, on the other hand, to be in somewhat better accord. It is therefore concluded that, despite its superficially intuitive appeal, the ring-current index is out of step both with $\pi$-electron partitions and $\Delta_{6}$-values as a general indicator of so-called "local aromaticity". (doi: 10.5562/cca1846)
\end{abstract}

Keywords: topological ring-current, $\pi$-electron partitions, delocalisation indices, benzenoid hydrocarbons, local aromaticity

\section{INTRODUCTION}

Polycyclic condensed benzenoid hydrocarbons (henceforth frequently referred to simply as benzenoids) have been intensely studied, largely because they are amongst the most stable hydrocarbons. Of the characteristic properties associated with conjugated systems, diamagnetic susceptibilities arising from $\pi$-electron ringcurrents ${ }^{1-4}$ have been considered as one of the main diagnostics of aromaticity ${ }^{5-7}$ - albeit a controversial one. ${ }^{8-11}$ However, because of the so-called multidimensional character of aromaticity, ${ }^{12-19}$ a quantitative measure requires the presence of several attributes, and this complicates quantitative assessments of the concept. One should note, however, that this multidimensional character has been discussed mostly for conjugated heterocycles, ${ }^{20-22}$ whilst the present paper is about benzenoid hydrocarbons. Furthermore, in addition to the global diamagnetic anisotropy, local $\pi$-electron ring-current intensities can be determined for each ring $^{1-4,8}$ of a conjugated network - in our case, a benzenoid system. In addition to the long-established criteria for aromaticity of continuous conjugation - stabilising resonance-energy, and a tendency towards bond-length equalisation in planar molecules - threedimensional aromaticity has also been established. ${ }^{23,24}$ In the present paper, however, we shall consider only benzenoids that are planar - or almost planar ${ }^{25,26}$ - in the geometrical sense, being formed from hexagonal rings that share carbon-carbon bonds; the molecular graphs that represent these structures are also planar in the graph-theoretical sense.

For a general condensed benzenoid hydrocarbon with $h$ benzenoid rings and $n$ carbon atoms, of which $a$ carbon atoms are internal ones - that is, adjacent to three other carbon atoms - the molecular formula is $\mathrm{C}_{4 h+2-a} \mathrm{H}_{2 h+4-a}$. We shall examine only two types of benzenoids: catafusenes (with no internal carbon atoms, $a=0$ ), and perifusenes (with $a>0$ ); moreover, we shall restrict the discussion to Kekuléan benzenoid structures $^{27}$ for which both $n$ and $a$ are even numbers and there are no odd electrons in their ground-state configurations built up by means of the Aufbau process. ${ }^{28-32} \mathrm{In}$ most of this paper, we shall confront two indices that characterise the individual rings of such benzenoid systems - namely, $\pi$-electron partitions ${ }^{33,34}$ and topolog-

\footnotetext{
* Author to whom correspondence should be addressed. (E-mail: R.B.Mallion@kent.ac.uk)
} 
ical $\pi$-electron ring-currents ${ }^{35}$ - seeking possible correlations between them. Later, we shall also consider the recently defined ${ }^{36}$ six-centre delocalisation-indices, $\Delta_{6}$.

\section{$\pi$-ELECTRON PARTITIONS, TOPOLOGICAL $\pi$-ELECTRON RING-CURRENTS, AND SIX- CENTRE DELOCALISATION-INDICES}

In several recent papers, ${ }^{33,34,37-43}$ an analysis of how $\pi$ electrons are shared amongst adjacent rings has led to material conclusions about what have been called " $\pi$ electron partitions" or " $\pi$-electron content", based on the following conventions: $:^{33,34}$

(i) in each resonance-structure of the benzenoid ring in question, a shared double-bond is considered to contribute one $\pi$-electron to each of the rings that share it;

(ii) a double bond that is not shared contributes both its $\pi$-electrons to the benzenoid ring in which it is situated;

(iii) all resonance structures are taken to have equal weights in the global partition of the $n \pi$-electrons of a given benzenoid-molecule.

It should be noted that benzene itself is the benzenoid structure having associated with it the highest-possible value (6) that a $\pi$-electron partition may assume, because the six $\pi$-electrons in benzene are not shared with any adjacent ring. We should, however, emphasise the following very important quantitative difference between the possible numerical values of $\pi$ electron partitions and the values that (topological) $\pi$ electron ring-currents may themselves take on. Topological $\pi$-electron ring-currents are, by their very definition, ${ }^{35}$ expressed as a ratio to the ring-current intensity calculated, by the same method, for benzene. This difference in the numerical values of partitions and ringcurrents is thus as follows: $\pi$-electron partitions lie between 0 and 6 (with the value 6 occurring solely in the case of benzene); on the other hand, ring-current intensities, expressed as a ratio to the similarly-calculated benzene-value, are pure, dimensionless numbers that can be (and frequently are) ${ }^{35}$ greater than $1-i . e$. , are greater than the ring-current intensity calculated, by the same method, for benzene. From the data presented by Mandado et al., ${ }^{36}$ the six-centre delocalisation-index $\Delta_{6}$ appears - like the $\pi$-electron partitions discussed above - to be a maximum in the case of benzene; $\Delta_{6}=0.0484$ for benzene and the index takes on values in the range $0.0037-0.0358$ for the 81 symmetrically non-equivalent rings in the other 26 benzenoids studied by those authors. ${ }^{36}$ Because these are small numbers, we shall find it convenient, in our tables and discussion in this paper, to deal with the $\Delta_{6}$-indices that have been arbitrarily multiplied by 100 .
There is a marked parallelism between Clar's theoretical qualitative ideas, ${ }^{27}$ and the quantitative $\pi$ electron partitions of benzenoids ${ }^{33,34,37,44}$ - as is argued in several recent articles. ${ }^{45-48}$ In the present paper, we now examine correlations between $\pi$-electron ringpartitions $^{33,34,44}$ and $\pi$-electron ring-current intensities calculated by means of the simple Hückel $^{49,50}$ London $^{51}-$ Pople $^{52}-$ McWeeny ${ }^{53}$ model (hereafter denoted "HLPM"). One of us (R. B. M.) has recently published $^{35}$ an extensive table of such ("topological" ${ }^{35}$ ) ring-current intensities for a large number of condensed, benzenoid hydrocarbons, each expressed as a ratio to the ring-current intensity calculated, by the same method, for benzene. Topological ring-currents are defined ${ }^{35}$ as being $\pi$-electron ring-current intensities - initially, specifically within the class of the condensed, benzenoid hydrocarbons (though this restriction has recently been relaxed $^{54}$ ) - that:

(a) are calculated by an application of the HLPM method, and

(b) are such that all Hückel Coulomb-integrals are assigned the value $(\alpha)$ appropriate for a carbon atom in benzene, and all resonance integrals are likewise set equal to the standard value $(\beta)$ for a carbon-carbon bond in benzene, and

(c) are based on a molecular geometry that is assumed to consist of regular hexagons of benzene dimensions, and, finally,

(d) are expressed as a ratio to the corresponding ringcurrent intensity evaluated, by the same method, for benzene.

Once a particular benzenoid hydrocarbon has been specified, such topological ring-currents are predetermined and do not further depend on any subjective (or other) parameters $;{ }^{35}$ they are, therefore, purely graphtheoretical indices, reliant solely on knowledge of a vertex-adjacency matrix ${ }^{55}$ for the graph representing the connectivity of the carbon atoms in the benzenoid molecule under study. ${ }^{56,57}$ Ring-current intensities calculated and presented in this way are what have been referred to $^{35}$ as topological $\pi$-electron ring-currents. All the ring-current intensities reported in Ref. 35, some of which are used here, are consistently of this type.

It may be observed that, in order to be in a position to calculate a topological ring-current, ${ }^{35}$ it is necessary to have knowledge of a well-defined, ground-state $\pi$-electronic-configuration for the conjugated system in question, such as is obtained from an application of the Aufbau Principle. It has been argued ${ }^{28-32}$ that the Aufbau process may itself be simulated by means of what may be considered as an entirely topological algorithm.

In order to explore more deeply how ring types affect the local aromaticity we add to our consideration a 
third criterion for local aromaticity in polycyclic benzenoids; this is based on the Mulliken approach and the quantum theory of atoms in molecules (QTAIM) and it is expressed by means of the six-centre delocalisation-indices (denoted as $\Delta_{6}^{\text {Mull }}$ and $\Delta_{6}^{\text {QTAIM }}$, respectively) recently introduced by Mandado and coworkers. ${ }^{36}$ The former values, $\Delta_{6}^{\text {Mull }}$ - here denoted simply as $\Delta_{6}-$ were calculated by Mandado et al. ${ }^{36}$ for a more numerous set of benzenoids than were $\Delta_{6}^{\text {QTAIM }}$-values; the $\Delta_{6}^{\text {Mull }}$-indices are, therefore, the ones that we adopt here. The definition of the six-centre delocalisation-indices, $\Delta_{6}$, regarded as a measure of "aromaticity" for individual rings, is presented in detail in Ref. 36 .

\section{DATA FOR $\pi$-ELECTRON PARTITIONS, TOPO- LOGICAL $\pi$-ELECTRON RING-CURRENTS AND SIX-CENTRE DELOCALISATION INDICES}

The numerical values of the $\pi$-electron partitions used here are taken from two previous papers by one of us (A. T. B.) and Randic. ${ }^{33,34}$ When there are differences between the $\pi$-electron partitions to be found in Refs. 33 and 34 and those presented in the tables that feature in the current paper, these are either (a) due to the correction of misprints in Refs. 33 and 34, and/or (b) arise because those elements of the data from Refs. 33 and 34 that were there quoted to four significant-figures have, for consistency, been rounded to just three significantfigures, here.

Data on topological $\pi$-electron ring-currents have been taken from the compilation recently published ${ }^{35}$ by the second author (R. B. M.). Again, for consistency, all topological ring-currents are here expressed to three significant-figures - regardless of any greater accuracy claimed in connexion with some of the structures listed in Ref. 35 - in order to be in accord with the number of significant figures to which all the $\pi$-electron partitions are quoted in the present paper. What we are here calling the six-centre $\Delta_{6}$-indices are the corresponding $\Delta_{6}^{\text {Mull }}$-values - likewise expressed to three significantfigures - taken from the paper by Mandado et al. ${ }^{36}$

\section{NOMENCLATURE FOR STRUCTURES AND CLASSIFICATION OF RINGS}

As already mentioned, when dealing with the condensed, benzenoid hydrocarbons it is often the convention to divide them into what are called "cata" structures (such as, for example, naphthalene), which possess only peripheral carbon-atoms, and "peri" structures (such as, for example, pyrene), which contain one or more internal carbon-atoms - see, for example, Refs. 27 and 58. An equivalent and more powerful classification is based on a diagram called the "dualist" (or "characteristic graph"). ${ }^{59}$ This is a depiction that consists of points ("vertices") and lines ("edges") in which the vertices are placed at the centres of a given structure's constituent benzenoid-rings, and the edges of the dualist diagram connect those vertices of the dualist diagram that correspond to adjacent rings (that is, rings sharing at least one bond) in the conjugated system under study. Catacondensed benzenoids have acyclic dualist diagrams, peri-condensed benzenoids have dualist diagrams with triangles, and the dualist diagrams of corona-condensed benzenoids possess larger rings. We adopt this categorisation here. The dualist diagram ("characteristic graph" ${ }^{19}$ ) is not actually a graph as such, in the normal graph-theoretical sense, for - in contradistinction to what is the case with genuine graphs - the angles between the lines representing the edges of dualist diagrams do matter. These angles are material to the information about the associated conjugated structure that the dualist diagram conveys. In a sense, therefore, the dualist diagram - originally (mis)named as the "characteristic graph" ${ }^{59}$ of a conjugated system - is essentially what, in graph theory, would be called the "inner dual"60 of the molecular graph representing the structure in question, but with the further imposition of prespecified angles between the edges of the inner dual.

As is clear from Figure 1, the anthracene and phenanthrene molecular-graphs have different dualist diagrams (Figures $1 \mathrm{a}$ and $1 \mathrm{~b}$, respectively) but the same inner dual (Figure 1c). The vertex degrees of dualist diagrams (that is, the number of edges incident on each vertex of the given dualist in question) have a particular significance for ring types, as will now be indicated.

We shall find that it is also convenient to classify individual rings according to the local geometrical environment in which they are situated within the given condensed benzenoid hydrocarbon under consideration.

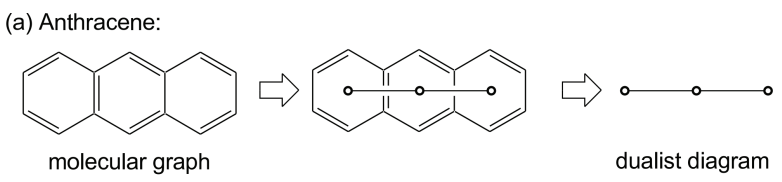

(b) Phenanthrene:

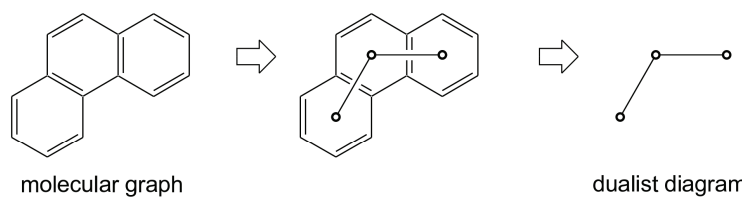

(c) A graph that represents the inner dual for both anthracene and phenanthrene:

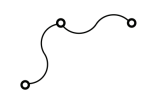

Figure 1. The Dualist Diagram for anthracene (a) and phenanthrene (b), together with the Inner Dual of both (c). 
A six-membered ring in such a structure can have anything from one to six adjacent rings and, according to the mutual positions of these rings, various ring types can be distinguished; even once- or twice-removed rings (i.e., rings that are not adjacent but are separated by one or two intervening rings) exert a certain influence. The several ring-types are denoted by letters (and, for onceor twice-removed non-adjacent rings, by primed or double-primed letters). Rings are thus categorised and labelled as $a, a^{\prime}, a^{\prime \prime}, b, c, d, d^{\prime}, d^{\prime \prime}, e, f, g, h, i, j, k$, and $l$. The twelve ring types in question (with $a$ and $d$ having two sub-types each) are defined (as the unshaded ring, in each case) in Figure 2. It should be noted that, of the molecules that we are dealing with here, rings of types $a, a^{\prime}, c, d, d^{\prime}$, and $g$ may occur in both cata- and peristructures; those of types $a^{\prime \prime}, b, e, f, h, i, j, k$, and $l$ can arise only in peri-structures; and rings of type $d^{\prime \prime}$ and $g$ will be found only in cata-structures. If, however, we had dealt with benzenoid hydrocarbons having more than seven rings, those rings categorised as being of types $d^{\prime \prime}$ and $g$ could occur in peri-structures as well as cata ones.

It is expected that a benzenoid ring will be influenced by the number and position of the rings adjacent to it; it will be seen that, for two exceptional types, $a$ and $d$, the influence of rings next to immediatelyadjacent ones is also felt. In order better to delineate various types, several identical sub-types are displayed in Figure 2, with the corresponding letter enclosed in square brackets.
Figure 2 shows what we are calling the twelve "types" of benzenoid rings, denoted by letters $a$ to $l$, and four "sub-types", denoted by prime and double-prime symbols (sixteen, therefore, in all) that will be seen to be revealed by a comparison between topological $\pi$ electron ring-currents and $\pi$-electron partitions. The types are discriminated by the degree of the vertex in the dualist diagram ${ }^{59}$ corresponding to a given ring (the unshaded ring in each part of Figure 2), whereas subtypes occur in two cases (for types $a$ and $d$ ). Descriptions of each of these ring types are listed in Table 1, which should be studied in conjunction with Figure 2.

\section{ISOARITHMIC STRUCTURES}

By virtue of the arithmetically rather simple, virtually "pencil-and-paper", definition of $\pi$-electron partitions, ${ }^{33,34,37,38}$ there exist families of structures amongst the condensed benzenoid hydrocarbons which, though distinct conjugated systems, have identical $\pi$-electronpartition values for their corresponding constituentrings. ${ }^{33,34} \mathrm{We}$ call such structures "isoarithmic". ${ }^{61,62}$

The topological $\pi$-electron ring-current intensity is, by contrast, a somewhat more-sophisticated index. It is dependent, in a rather subtle and intricate way, ${ }^{35,49-}$ $54,56,57$ on the eigenvalues and eigenvectors of an adjacency matrix ${ }^{55}$ of the graph representing the carbonatom connectivity of the condensed, benzenoid hydrocarbon under study (as well as on a knowledge of the

Table 1. Classification of Ring Types. (Please study in conjunction with Figure 2)

\begin{tabular}{|c|c|}
\hline Types & Description of vertex degree and the corresponding context in the dualist diagram \\
\hline Type $a$ & degree 1 acenic (linear condensation $-180^{\circ}$ angle in the dualist diagram) \\
\hline Type $a^{\prime}$ & degree 1 phenanthrenic, triphenylenic or pyrenic (kinked $-120^{\circ}$ angle in the dualist diagram) \\
\hline Type $a^{\prime \prime}$ & degree 1 pyrenic on the symmetry axis \\
\hline Type $b$ & degree 2 vicinal (a vertex of a triangle in a perifusene dualist diagram) \\
\hline Type $c$ & degree 2 phenanthrenic \\
\hline Type $d$ & degree 2 anthracenic (doubly-kinked at both anthracenic end-rings) \\
\hline Type $d^{\prime}$ & degree 2 anthracenic (singly-kinked at one of the anthracenic end-rings) \\
\hline Type $d^{\prime \prime}$ & degree 2 acenic (tetracenic or acenic in general) \\
\hline Type $e$ & degree 3 vicinal (a vertex of two condensed triangles in a perifusene dualist diagram) \\
\hline Type $f$ & degree 3 (by means of degree 2 and degree 1 ) \\
\hline Type $g$ & degree 3 triphenylenic (the central ring in a triphenylenic sub-diagram within the dualist diagram) \\
\hline Type $h$ & degree 4 vicinal (a vertex of 3 condensed triangles in a perifusene dualist diagram) \\
\hline Type $i$ & degree 4 non-vicinal (by means of degree 3 and degree 1 ) \\
\hline Type $j$ & degree 4 non-vicinal (by means of degree 2 and degree 2) \\
\hline Type $k$ & degree 5 \\
\hline Type $l$ & degree 6 \\
\hline
\end{tabular}


<smiles>C1CCC2CC3CCCCC3CC2C1</smiles>

a<smiles>C1CC2CCCC3CCCC(C1)C23</smiles>

$b$<smiles>C1CCC2CC3CCCCC3CC2C1</smiles>

$\left[d^{\prime}\right.$<smiles>C1CC2CCC3CCCC4CCC(C1)C2C34</smiles>

e<smiles>C1CCC2C3CCCC4CCCC5CCC(C1)C2C5C43</smiles>

i<smiles>C1CCC2C(C1)CCC1CCCCC12</smiles>

$\left[a^{\prime}\right.$<smiles>C1CCC2C(C1)CCC1CCCCC12</smiles>

C<smiles>C1CC2CC(C1)CC1C3CCCCC3C3CCCCC3C1C2</smiles>

$d^{\prime}$<smiles>C1CCC2C(C1)CC1CCCC3C1CCCC23</smiles>

$f$

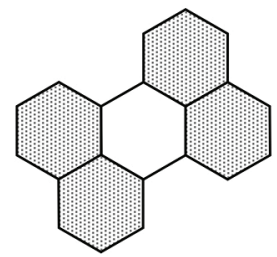

j

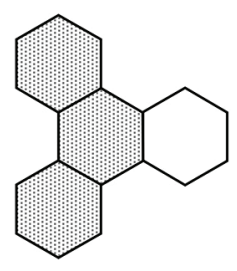

$a^{\prime}$<smiles>C1CCC2C(C1)CC1CCC3CCCC4CCC2C3C41</smiles>

$\left.a^{\prime}\right]$

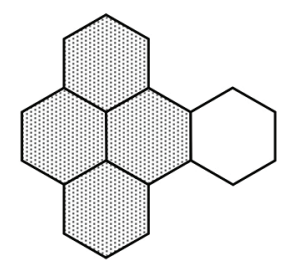

a"

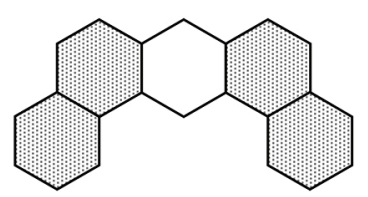

$[d$

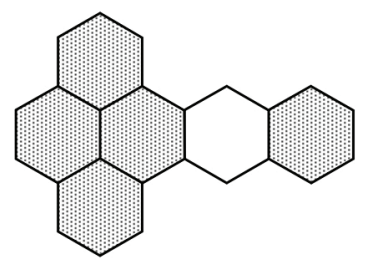

$\left.d^{\prime}\right]$<smiles>C1CCC2C(C1)C1CCCCC1C1CCCCC21</smiles>

g

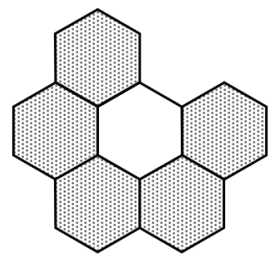

k<smiles>C1CCC2C(C1)CCC1CC3C4CCCCC4C4CCCCC4C3CC12</smiles>

d]<smiles>C1CCC2CC3CC4CCCCC4CC3CC2C1</smiles>

$d^{\prime \prime}$

h

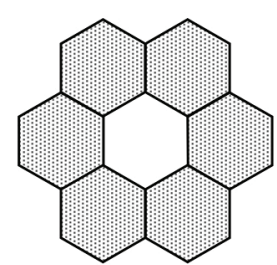

I

Figure 2. Ring types (denoted by letters) and sub-types (denoted by prime or double prime symbols). In each case, the unshaded ring is the ring being categorised. 
ground-state $\pi$-electronic-configuration for the system) ${ }^{28-32}$ Because of this (on grounds of differences in symmetry, for one thing), the corresponding rings of isoarithmic structures are by no means guaranteed to have associated with them identically the same topological $\pi$-electron ring-currents. That said, however, it is a remarkable fact that, in practice, the topological $\pi$-electron ring-currents in the respective rings of isoarithmic structures seem frequently to differ only in the third decimal-place.

This phenomenon is well illustrated by Figure 3, which depicts the topological ring-currents in three pairs of isoarithmic structures, and one family of greater multiplicity (a triplet). Exceptionally, where they are available in the literature ${ }^{35}$ to this accuracy, some ringcurrent values in this Figure are quoted to three decimal-places; this third decimal-place is included in order to show just how fine and sensitive are the differences in topological $\pi$-electron ring-current intensities between the corresponding rings of structures that, so far as $\pi$-electron partitions are concerned, constitute families of isoarithmic systems where $\pi$-electron partitions are precisely the same. Because the differences in topological ring-current intensities between the respective corresponding rings of each family of isoarithmic structures are comparatively so small, only one of each isoarithmic pair/multiple will be included in the comparative tables and plots that are to follow in this paper.

\section{CONFRONTATION OF $\pi$-ELECTRON PARTI- TIONS AND THE CORRESPONDING TOPO- LOGICAL $\pi$-ELECTRON RING-CURRENTS}

Table 2 illustrates $\pi$-electron partitions and the corresponding topological $\pi$-electron ring-currents for 103 distinct rings in 27 different non-isoarithmic catacondensed structures and for 73 distinct rings in 16 different peri-condensed benzenoids with up to seven rings. The partitions data are taken from Refs. 33 and 34 , and the ring-current values are from the compilation presented in Ref. 35. It should be noted that (a) compound numberings follow Ref. 33 for the cata-structures and Ref. 34 (where the same numbers are repeated) for the peri ones, and (b) these numbers do not run consecutively within each category of structure. The latter is because not every structure treated in Refs. 33 and 34 has corresponding ring-current data listed for it in Ref. 35 and, naturally, we are dealing here only with those structures for which data are available on both indices. Here, the labellings of the cata- structures will be preceded by the letter " $\mathrm{C}$ ", and will be written in blue, in bold type; peri-structures will be labelled with a bold number written in red, and preceded by the letter "P". This is merely a convenience as far as the structure labellings are concerned but, in the plots of ring currents $v s$. electron partitions, presented later, the use of colour

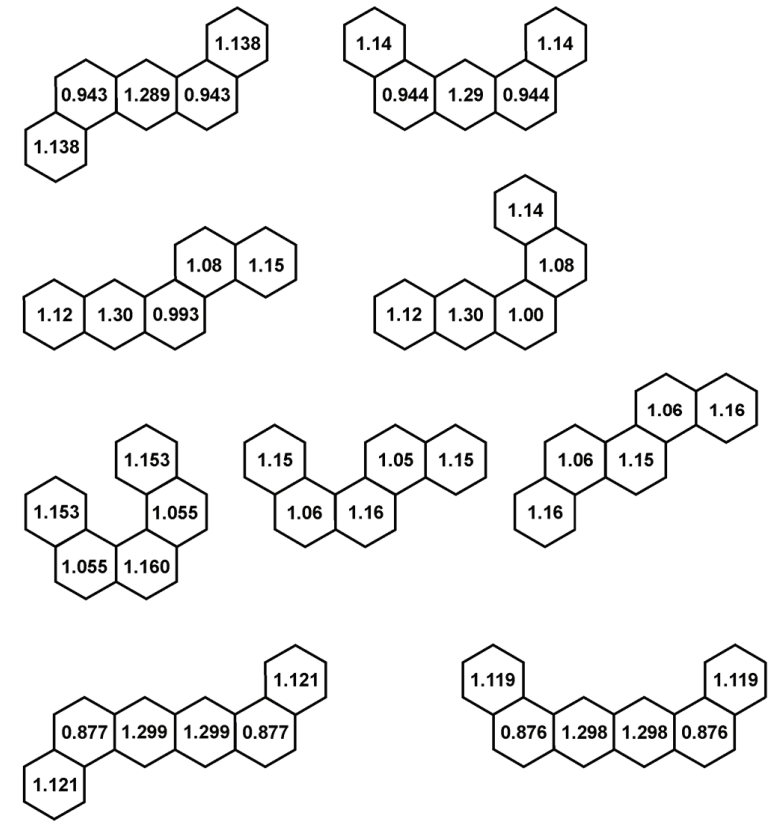

Figure 3. Three pairs and a triplet of isoarithmic benzenoids, together with the intensities of the topological $\pi$-electron ringcurrents borne by each of their constituent rings (indicated within the respective rings).

will be seen to be essential. The number, $K$, of resonance (or Kekulé) structures is presented in a separate column in Table 2, because it serves as an ordering criterion for isomeric benzenoids having the same number of rings.

Table 3 presents data for what we are going to refer to as "anomalous" polycyclic benzenoids, which lead to outliers in our plots. The anomalous perifusenes have localised bonds (such as zethrene (P5) or its benzologue (P19)), essential single-bonds (such as perylene (P2) or its benzologs (P12) and (P55)), and unique environments, such as coronene $(\mathbf{P 3 5})$.

\section{"FRAGMENTED" LINEAR-CORRELATIONS OF $\pi$-ELECTRON PARTITIONS AND TOPOLOGI- CAL $\pi$-ELECTRON RING-CURRENTS}

In Figure 4 we present a plot of topological $\pi$-electron ring-currents $v s$. $\pi$-electron partitions using all the data from Table 2. It can be seen that there are several distinct regions of the diagram where there are linear correlations. However, the most striking aspect is that, amongst what we are calling here these "fragmented" linear-correlations (where correlations are limited to being within certain types of ring), some have positive slopes - as expected if the aromaticity due to delocalised $\pi$-electrons were "uni-dimensional" - whereas, surprisingly, a few of the others even have negative slopes. In Table 4, these fragmented linear-correlations 
Table 2. $\pi$-Electron partitions and the corresponding topological $\pi$-electron ring-currents for 103 distinct rings in 27 different cata-condensed structures and for 73 distinct rings in 16 different peri-condensed benzenoids. The partitions data are taken from Refs. 33 and 34, and the ring-current values are from the compilation presented in Ref. 35

\begin{tabular}{|c|c|c|c|c|c|c|}
\hline Compound & $K$ & Ring & Partition & Ring Current & Ring Type & Structure \\
\hline $\mathrm{C} 1$ & 3 & AA & 5.00 & 1.09 & $a$ & \\
\hline \multirow[t]{2}{*}{$\mathrm{C} 2$} & 4 & AA & 4.75 & 1.09 & $a$ & \\
\hline & & B & 4.50 & 1.28 & $d^{\prime \prime}$ & \\
\hline \multirow[t]{2}{*}{$\mathrm{C} 3$} & 5 & AA & 5.20 & 1.13 & $a^{\prime}$ & \\
\hline & & $\mathrm{B}$ & 3.60 & 0.975 & $c$ & \\
\hline \multirow[t]{2}{*}{$\mathrm{C} 4$} & 5 & AA & 4.60 & 1.07 & $a$ & \\
\hline & & $\mathrm{BB}$ & 4.40 & 1.31 & $d^{\prime \prime}$ & \\
\hline \multirow[t]{4}{*}{ C5 } & 7 & A & 4.86 & 1.12 & $a$ & \\
\hline & & $\mathrm{B}$ & 4.57 & 1.27 & $d^{\prime}$ & \\
\hline & & $\mathrm{C}$ & 3.29 & 0.891 & $c$ & \\
\hline & & $\mathrm{D}$ & 5.29 & 1.12 & $a^{\prime}$ & \\
\hline \multirow[t]{2}{*}{ C6 } & 8 & AA & 5.13 & 1.15 & $a^{\prime}$ & \\
\hline & & $\mathrm{BB}$ & 3.88 & 1.07 & $c$ & \\
\hline \multirow[t]{2}{*}{$\mathrm{C} 7$} & 9 & AAA & 5.33 & 1.11 & $a^{\prime}$ & \\
\hline & & $\mathrm{B}$ & 2.00 & 0.747 & $g$ & \\
\hline \multirow[t]{3}{*}{$\mathrm{C8}$} & 6 & $\mathrm{AA}$ & 4.50 & 1.06 & $a$ & \\
\hline & & $\mathrm{BB}$ & 4.33 & 1.30 & $d^{\prime \prime}$ & \\
\hline & & $\mathrm{C}$ & 4.33 & 1.35 & $d^{\prime \prime}$ & \\
\hline \multirow[t]{5}{*}{ C9 } & 9 & A & 4.67 & 1.09 & $a$ & \\
\hline & & $\mathrm{B}$ & 4.44 & 1.32 & $d^{\prime \prime}$ & \\
\hline & & $\mathrm{C}$ & 4.44 & 1.35 & $d^{\prime \prime}$ & \\
\hline & & $\mathrm{D}$ & 3.11 & 0.847 & $c$ & \\
\hline & & $\mathrm{E}$ & 5.33 & 1.11 & $a^{\prime}$ & \\
\hline \multirow[t]{3}{*}{ C10 } & 10 & AA & 4.90 & 1.11 & $a$ & \\
\hline & & $\mathrm{BB}$ & 4.60 & 1.23 & $d^{\prime}$ & \\
\hline & & $\mathrm{C}$ & 3.00 & 0.784 & $c$ & \\
\hline \multirow[t]{5}{*}{ C11 } & 11 & A & 4.82 & 1.12 & $a$ & \\
\hline & & B & 4.55 & 1.30 & $d^{\prime}$ & \\
\hline & & $\mathrm{C}$ & 3.55 & 0.993 & $c$ & \\
\hline & & $\mathrm{D}$ & 4.00 & 1.08 & $c$ & \\
\hline & & $\mathrm{E}$ & 5.09 & 1.15 & $a^{\prime}$ & \\
\hline \multirow[t]{3}{*}{ C12 } & 12 & AA & 5.25 & 1.14 & $a^{\prime}$ & \\
\hline & & $\mathrm{BB}$ & 3.42 & 0.944 & $c$ & \\
\hline & & $\mathrm{C}$ & 4.67 & 1.29 & $d$ & \\
\hline \multirow[t]{3}{*}{ C13 } & 13 & AA & 5.15 & 1.16 & $a^{\prime}$ & \\
\hline & & BB & 3.77 & 1.06 & $c$ & \\
\hline & & $\mathrm{C}$ & 4.15 & 1.15 & $c$ & \\
\hline \multirow[t]{4}{*}{ C14 } & 13 & A & 4.92 & 1.12 & $a$ & \\
\hline & & B & 4.62 & 1.21 & $d^{\prime}$ & \\
\hline & & $\mathrm{C}$ & 1.69 & 0.648 & $g$ & \\
\hline & & DD & 5.39 & 1.08 & $a$ & \\
\hline \multirow[t]{5}{*}{ C15 } & 14 & A & 5.07 & 1.10 & $a^{\prime}$ & \\
\hline & & B & 4.07 & 1.09 & $c$ & \\
\hline & & $\mathrm{C}$ & 2.29 & 0.853 & $g$ & \\
\hline & & $\mathrm{D}$ & 5.29 & 1.14 & $a^{\prime}$ & \\
\hline & & $\mathrm{E}$ & 5.29 & 1.13 & $a^{\prime}$ & \\
\hline
\end{tabular}


Table 2. Continued

\begin{tabular}{|c|c|c|c|c|c|c|}
\hline Compound & K & Ring & Partition & Ring Current & Ring Type & Structure \\
\hline \multirow{3}{*}{ C16 } & 7 & AA & 4.43 & 1.05 & $a$ & \multirow{3}{*}{ 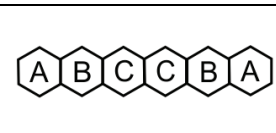 } \\
\hline & & $\mathrm{BB}$ & 4.29 & 1.29 & $d^{\prime \prime}$ & \\
\hline & & $\mathrm{CC}$ & 4.29 & 1.35 & $d^{\prime \prime}$ & \\
\hline \multirow[t]{6}{*}{ C17 } & 11 & A & 4.55 & 1.07 & $a$ & \multirow{6}{*}{ AXOCODYE } \\
\hline & & B & 4.36 & 1.32 & $d^{\prime \prime}$ & \\
\hline & & $\mathrm{C}$ & 4.36 & 1.36 & $d^{\prime \prime}$ & \\
\hline & & D & 4.36 & 1.24 & $d^{\prime \prime}$ & \\
\hline & & E & 3.00 & 0.825 & $c$ & \\
\hline & & F & 5.36 & 1.10 & $a^{\prime}$ & \\
\hline \multirow[t]{6}{*}{ C18 } & 13 & A & 4.69 & 1.09 & $a$ & \multirow{6}{*}{ A) B.COD } \\
\hline & & B & 4.46 & 1.31 & $d^{\prime \prime}$ & \\
\hline & & $\mathrm{C}$ & 4.46 & 1.22 & $d^{\prime \prime}$ & \\
\hline & & D & 2.85 & 0.732 & $c$ & \\
\hline & & E & 4.62 & 1.21 & $d^{\prime}$ & \\
\hline & & $\mathrm{F}$ & 4.92 & 1.11 & $a$ & \\
\hline \multirow[t]{3}{*}{$\mathrm{C2O}$} & 15 & $\mathrm{AA}$ & 4.80 & 1.12 & $a$ & \multirow{3}{*}{$\widehat{A} \widehat{B}|\widehat{C}| \widehat{C} \widehat{B} \mid \hat{A}$} \\
\hline & & $\mathrm{BB}$ & 4.53 & 1.31 & $d^{\prime}$ & \\
\hline & & $\mathrm{CC}$ & 3.67 & 1.01 & $c$ & \\
\hline \multirow[t]{3}{*}{$\mathrm{C} 21$} & 16 & $\mathrm{AA}$ & 5.31 & 1.12 & $a^{\prime}$ & \multirow{3}{*}{$\widehat{A}(B)(C) \widehat{B}$} \\
\hline & & $\mathrm{BB}$ & 3.19 & 0.876 & $c$ & \\
\hline & & $\mathrm{CC}$ & 4.50 & 1.30 & $d^{\prime \prime}$ & \\
\hline \multirow[t]{6}{*}{$\mathrm{C} 22$} & 17 & $\mathrm{~A}$ & 4.88 & 1.12 & $a$ & \multirow{6}{*}{ A) B C C } \\
\hline & & B & 4.59 & 1.26 & $d^{\prime}$ & \\
\hline & & $\mathrm{C}$ & 3.12 & 0.839 & $c$ & \\
\hline & & D & 4.71 & 1.26 & $d$ & \\
\hline & & E & 3.47 & 0.951 & $c$ & \\
\hline & & F & 5.24 & 1.14 & $a$ & \\
\hline \multirow[t]{5}{*}{$\mathrm{C} 23$} & 17 & A & 4.71 & 1.09 & $a$ & \multirow{5}{*}{ AXBCOCO } \\
\hline & & B & 4.47 & 1.31 & $d^{\prime \prime}$ & \\
\hline & & $\mathrm{C}$ & 4.47 & 1.19 & $d^{\prime \prime}$ & \\
\hline & & D & 1.53 & 0.603 & $g$ & \\
\hline & & $\mathrm{EE}$ & 5.41 & 1.06 & $a^{\prime}$ & \\
\hline \multirow[t]{6}{*}{$\mathrm{C} 24$} & 18 & A & 4.83 & 1.13 & $a$ & \multirow{6}{*}{ AXBC } \\
\hline & & B & 4.56 & 1.30 & $d^{\prime}$ & \\
\hline & & $\mathrm{C}$ & 3.44 & 0.973 & $c$ & \\
\hline & & D & 4.28 & 1.15 & $c$ & \\
\hline & & E & 3.72 & 1.04 & $c$ & \\
\hline & & $\mathrm{F}$ & 5.17 & 1.15 & $a^{\prime}$ & \\
\hline \multirow[t]{6}{*}{$\mathrm{C} 25$} & 19 & A & 5.26 & 1.14 & $a^{\prime}$ & \multirow{6}{*}{ (A)COD } \\
\hline & & B & 3.37 & 0.936 & $c$ & \\
\hline & & $\mathrm{C}$ & 4.63 & 1.31 & $d$ & \\
\hline & & $\mathrm{D}$ & 3.68 & 1.05 & $c$ & \\
\hline & & E & 3.95 & 1.08 & $c$ & \\
\hline & & $\mathrm{F}$ & 5.11 & 1.15 & $a^{\prime}$ & \\
\hline \multirow[t]{4}{*}{$\mathrm{C} 27$} & 19 & $\mathrm{AA}$ & 4.95 & 1.10 & $a$ & \multirow{4}{*}{ ÂCOC } \\
\hline & & $\mathrm{BB}$ & 4.63 & 1.17 & $d^{\prime}$ & \\
\hline & & $\mathrm{C}$ & 1.42 & 0.548 & $g$ & \\
\hline & & D & 5.42 & 1.04 & $a^{\prime}$ & \\
\hline
\end{tabular}


Table 2. Continued

\begin{tabular}{|c|c|c|c|c|c|c|}
\hline Compound & $K$ & Ring & Partition & Ring Current & Ring Type & Structure \\
\hline \multirow[t]{3}{*}{$\mathrm{C} 29$} & 21 & AA & 5.14 & 1.16 & $a^{\prime}$ & \\
\hline & & $\mathrm{BB}$ & 3.81 & 1.07 & $c$ & \\
\hline & & $\mathrm{CC}$ & 4.05 & 1.15 & $c$ & \\
\hline \multirow[t]{6}{*}{ C30 } & 22 & $\mathrm{~A}$ & 5.23 & 1.14 & $a^{\prime}$ & \\
\hline & & $\mathrm{B}$ & 3.50 & 0.962 & $c$ & \\
\hline & & $\mathrm{C}$ & 4.73 & 1.25 & $d$ & \\
\hline & & $\mathrm{D}$ & 1.82 & 0.698 & $g$ & \\
\hline & & $\mathrm{E}$ & 5.36 & 1.09 & $a^{\prime}$ & \\
\hline & & $\mathrm{F}$ & 5.36 & 1.10 & $a^{\prime}$ & \\
\hline \multirow[t]{2}{*}{ P1 } & 6 & AA & 4.67 & 1.33 & $b$ & \\
\hline & & $\mathrm{BB}$ & 3.33 & 0.964 & $e$ & \\
\hline \multirow[t]{5}{*}{ P3 } & 9 & $\mathrm{~A}$ & 5.00 & 1.21 & $a^{\prime}$ & \\
\hline & & $\mathrm{B}$ & 3.67 & 1.29 & $f$ & \\
\hline & & $\mathrm{C}$ & 3.11 & 0.848 & $e$ & \\
\hline & & $\mathrm{D}$ & 4.67 & 1.30 & $b$ & \\
\hline & & $\mathrm{E}$ & 3.56 & 1.08 & $e$ & \\
\hline \multirow[t]{4}{*}{ P4 } & 11 & A & 5.36 & 1.10 & $a^{\prime \prime}$ & \\
\hline & & $\mathrm{B}$ & 1.82 & 0.719 & $i$ & \\
\hline & & $\mathrm{CC}$ & 4.73 & 1.29 & $b$ & \\
\hline & & $\mathrm{D}$ & 3.36 & 0.987 & $e$ & \\
\hline \multirow[t]{3}{*}{ P6 } & 10 & $\mathrm{AA}$ & 4.60 & 1.34 & $b$ & \\
\hline & & $\mathrm{BB}$ & 3.30 & 1.30 & $h$ & \\
\hline & & $\mathrm{CC}$ & 3.10 & 0.854 & $e$ & \\
\hline \multirow[t]{6}{*}{ P8 } & 12 & A & 4.75 & 1.14 & $a$ & \\
\hline & & $\mathrm{B}$ & 4.50 & 1.37 & $d^{\prime}$ & \\
\hline & & $\mathrm{C}$ & 3.42 & 1.21 & $f$ & \\
\hline & & $\mathrm{D}$ & 3.00 & 0.790 & $e$ & \\
\hline & & $\mathrm{E}$ & 4.67 & 1.27 & $b$ & \\
\hline & & $\mathrm{F}$ & 3.67 & 1.09 & $e$ & \\
\hline \multirow[t]{3}{*}{ P9 } & 13 & $\mathrm{AA}$ & 4.92 & 1.20 & $a^{\prime}$ & \\
\hline & & $\mathrm{BB}$ & 3.77 & 1.31 & $f$ & \\
\hline & & $\mathrm{CC}$ & 3.31 & 0.979 & $e$ & \\
\hline \multirow[t]{4}{*}{ P10 } & 14 & $\mathrm{AA}$ & 5.07 & 1.19 & $a^{\prime}$ & \\
\hline & & $\mathrm{BB}$ & 3.57 & 1.21 & $f$ & \\
\hline & & $\mathrm{C}$ & 2.93 & 0.725 & $e$ & \\
\hline & & $\mathrm{D}$ & 3.79 & 1.18 & $e$ & \\
\hline \multirow[t]{4}{*}{ P11 } & 14 & $\mathrm{AA}$ & 4.71 & 1.29 & $b$ & \\
\hline & & $\mathrm{BB}$ & 3.50 & 1.08 & $e$ & \\
\hline & & $\mathrm{C}$ & 3.86 & 1.38 & $e$ & \\
\hline & & $\mathrm{D}$ & 1.71 & 0.684 & $k$ & \\
\hline \multirow[t]{6}{*}{ P14 } & 16 & A & 4.94 & 1.20 & $a^{\prime}$ & \\
\hline & & B & 3.81 & 1.33 & $f$ & \\
\hline & & $\mathrm{C}$ & 3.13 & 0.888 & $e$ & \\
\hline & & $\mathrm{D}$ & 4.75 & 1.30 & $b$ & \\
\hline & & $\mathrm{E}$ & 2.06 & 0.843 & $i$ & \\
\hline & & $\mathrm{F}$ & 5.31 & 1.13 & $a^{\prime \prime}$ & \\
\hline
\end{tabular}


Table 2. Continued

\begin{tabular}{|c|c|c|c|c|c|c|}
\hline Compound & $K$ & Ring & Partition & Ring Current & Ring Type & Structure \\
\hline \multirow[t]{5}{*}{ P15 } & 16 & $\mathrm{~A}$ & 4.94 & 1.11 & $a$ & \\
\hline & & $\mathrm{B}$ & 4.63 & 1.19 & $d^{\prime}$ & \\
\hline & & $\mathrm{C}$ & 1.56 & 0.614 & $i$ & \\
\hline & & $\mathrm{D}$ & 3.38 & 0.989 & $e$ & \\
\hline & & $\mathrm{EE}$ & 4.75 & 1.26 & $b$ & \\
\hline \multirow[t]{6}{*}{ P17 } & 17 & A & 5.06 & 1.20 & $a^{\prime}$ & \\
\hline & & $\mathrm{B}$ & 3.65 & 1.23 & $f$ & \\
\hline & & $\mathrm{C}$ & 3.59 & 1.09 & $e$ & \\
\hline & & $\mathrm{D}$ & 4.71 & 1.26 & $b$ & \\
\hline & & $\mathrm{E}$ & 1.59 & 0.606 & $i$ & \\
\hline & & $\mathrm{F}$ & 5.41 & 1.06 & $a^{\prime}$ & \\
\hline \multirow[t]{3}{*}{ P18 } & 20 & AA & 5.35 & 1.11 & $a^{\prime}$ & \\
\hline & & $\mathrm{BB}$ & 1.85 & 0.745 & $i$ & \\
\hline & & $\mathrm{CC}$ & 4.80 & 1.27 & $b$ & \\
\hline \multirow[t]{3}{*}{ P29 } & 18 & AA & 4.67 & 1.33 & $b$ & \\
\hline & & BBBB & 3.33 & 1.03 & $e$ & \\
\hline & & $\mathrm{C}$ & 3.33 & 1.45 & $j$ & \\
\hline \multirow[t]{7}{*}{ P40 } & 21 & A & 5.29 & 1.14 & $a^{\prime}$ & \\
\hline & & $\mathrm{B}$ & 3.29 & 0.932 & $c$ & \\
\hline & & $\mathrm{C}$ & 4.57 & 1.37 & $d$ & \\
\hline & & $\mathrm{D}$ & 3.52 & 1.26 & $f$ & \\
\hline & & $\mathrm{E}$ & 3.05 & 0.824 & $e$ & \\
\hline & & $\mathrm{F}$ & 4.67 & 1.29 & $b$ & \\
\hline & & G & 3.62 & 1.09 & $e$ & \\
\hline \multirow[t]{7}{*}{ P46 } & 23 & A & 4.78 & 1.14 & $a$ & \\
\hline & & $\mathrm{B}$ & 4.52 & 1.36 & $d^{\prime}$ & \\
\hline & & $\mathrm{C}$ & 3.39 & 1.14 & $f$ & \\
\hline & & $\mathrm{D}$ & 3.70 & 1.10 & $e$ & \\
\hline & & $\mathrm{E}$ & 4.70 & 1.23 & $b$ & \\
\hline & & $\mathrm{F}$ & 1.48 & 0.559 & $i$ & \\
\hline & & $\mathrm{G}$ & 5.44 & 1.04 & $a$ & \\
\hline \multirow[t]{5}{*}{ P60 } & 27 & AA & 5.11 & 1.18 & $a^{\prime}$ & \\
\hline & & BB & 3.56 & 1.16 & $f$ & \\
\hline & & $\mathrm{C}$ & 3.82 & 1.18 & $e$ & \\
\hline & & D & 1.41 & 0.508 & $i$ & \\
\hline & & $\mathrm{E}$ & 5.44 & 1.02 & $a^{\prime}$ & \\
\hline
\end{tabular}

are presented separately for some of the positive slopes and for all of the negative ones. In Figure 5, we illustrate the first three correlations of Table 4 that have positive slopes, which appear in the lower left ("SouthWest") part of Figure 4.

It can be seen from the part of Table 4 concerned with positive slopes that both the $\pi$-electron partitions and the topological $\pi$-electron ring-currents ascribe distinctly lower values to rings of types $g, i$, and $k$ (socalled "empty rings" in Clar's theory), ${ }^{27,58}$ as shown by Figures 2 and 4 . Terminal rings with degree 1 in acenic portions of catafusenes (type $a$ ) are, by contrast, assigned high values both by the topological $\pi$-electron ring-currents and the $\pi$-electron partitions.

Whilst linear correlations between ring currents and $\pi$-electron partitions within certain restricted classes of ring types displayed in Figure 5 are good (with correlation coefficients of up to 0.996), correlation coefficients for cata-rings $a(0.854)$ and for peri-rings $f$ (0.706) are decidedly weak. Correlation coefficients for the correlations that have negative slopes range from -0.996 for cata- and peri-rings-types $d$ down to -0.868 for the correlation attempted for ring types $a^{\prime}$ in the cata- and peri-structures combined. It can also be seen from Table 4 that the negative slope characterises terminal rings of degree 1 (types $a^{\prime}$ or $a^{\prime \prime}$ ) adjacent to a 
Table 3. "Anomalous" polycyclic benzenoids

\begin{tabular}{|c|c|c|c|c|c|c|}
\hline Compound & $K$ & Ring & Partition & Ring Current & Ring Type & Structure \\
\hline \multirow[t]{2}{*}{ P2 } & 9 & AAAA & 4.67 & 0.970 & $b$ & \\
\hline & & B & 1.33 & 0.239 & $j$ & \\
\hline \multirow[t]{3}{*}{ P5 } & 9 & AA & 4.67 & 0.922 & $b$ & \\
\hline & & $\mathrm{BB}$ & 4.67 & 0.865 & $b$ & \\
\hline & & $\mathrm{CC}$ & 2.67 & 0.365 & $f$ & \\
\hline \multirow[t]{6}{*}{ P12 } & 15 & $\mathrm{~A}$ & 5.20 & 1.08 & $a$ & \\
\hline & & $\mathrm{B}$ & 3.40 & 0.875 & $f$ & \\
\hline & & $\mathrm{C}$ & 4.80 & 1.04 & $b$ & \\
\hline & & $\mathrm{D}$ & 1.26 & 0.236 & $j$ & \\
\hline & & $\mathrm{E}$ & 4.68 & 0.973 & $b$ & \\
\hline & & $\mathrm{F}$ & 4.68 & 0.974 & $b$ & \\
\hline \multirow[t]{4}{*}{ P19 } & 9 & AA & 4.67 & 0.905 & $b$ & \\
\hline & & $\mathrm{BB}$ & 4.67 & 0.820 & $b$ & \\
\hline & & $\mathrm{CC}$ & 2.67 & 0.410 & $f$ & \\
\hline & & $\mathrm{D}$ & 4.00 & 0.577 & $d$ & \\
\hline \multirow[t]{2}{*}{ P35 } & 20 & AAAAAA & 3.70 & 1.46 & $e$ & \\
\hline & & $\mathrm{B}$ & 1.80 & 1.04 & $l$ & \\
\hline \multirow[t]{4}{*}{ P55 } & 25 & AA & 5.20 & 1.08 & $a$ & \\
\hline & & $\mathrm{BB}$ & 3.40 & 0.876 & $f$ & \\
\hline & & $\mathrm{CC}$ & 4.80 & 1.04 & $b$ & D \\
\hline & & $\mathrm{D}$ & 1.20 & 0.233 & $j$ & \\
\hline
\end{tabular}

benzenoid ring followed by a "kink" in catafusenes or perifusenes, as well as middle rings of degree 2 (type $d^{\prime}$ ). All these ring-types appear in the "North-East" part of Figure 4, characterised by the higher values of both topological $\pi$-electron ring-currents and $\pi$-electron partitions.

It has been established ${ }^{63}$ that, in terms (a) of energy criteria, (b) of chemical reactivity manifested by additions of hydrogen or halogens, and (c) of $\pi$-electron partitions, the aromaticity of the central ring in

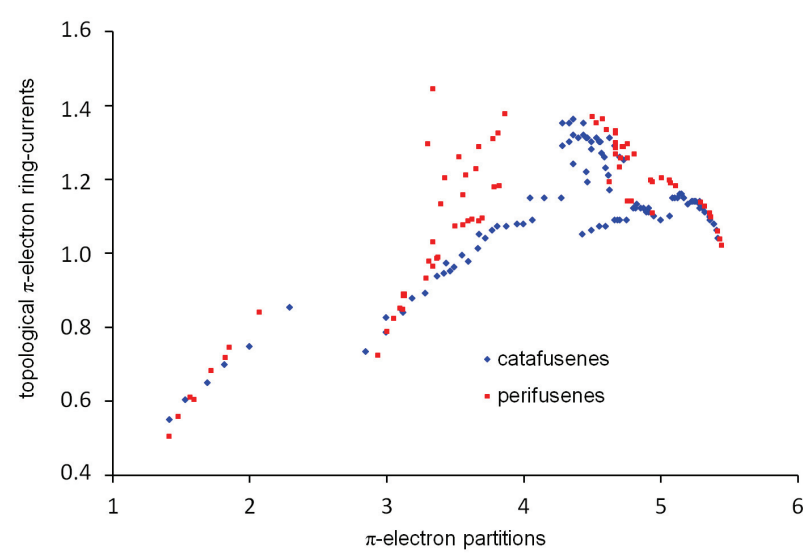

Figure 4. Plot of topological $\pi$-electron ring-currents (on the vertical axis) $v s$. $\pi$-electron partitions (along the horizontal axis) for catafusenes (blue points) and perifusenes (red points). anthracene or phenanthrene is lower than that of the terminal rings. However, as far as the topological $\pi$ electron ring-currents are concerned - if, indeed, one can properly take such quantities to be some sort of indication of "aromaticity" 8,11 - the opposite is true for anthracene (and other linear acenes), ${ }^{64}$ as can be seen from the data in Table 1, or from a comparison of the NICS values calculated by Schleyer and co-workers. ${ }^{65-}$ ${ }^{67}$ The present authors are inclined to view this observation as essentially another manifestation of the so-called "multi-dimensional" character of "aromaticity"11 - but see Ref. 15 for an alternative view.

\section{A THIRD KIND OF CORRELATION INVOLV- ING QUANTUM-CHEMICAL CRITERIA}

Ring currents calculated for polycyclic benzenoids by various methods frequently seem to provide results that are in conflict with intuitive representations of local aromaticity. ${ }^{8,11}$ Thus, as just mentioned, NICS values, ${ }^{65-67}$ or the topological $\pi$-electron ring-current intensities discussed in previous sections of the present study, indicate higher delocalisation for the central rings of anthracene and phenanthrene than for the marginal ones. However, bond distances and chemical reactivities show that the central rings are prone to 1,4- and 1,2-additions, respectively, revealing their dienic or alkenic character, 
Table 4. "Fragmented" linear-correlations ${ }^{(a),(b)}$ (see text) of topological $\pi$-electron ring-currents ${ }^{35}$ (as the dependent variable) $v s$. $\pi$-electron partitions ${ }^{33,34}$ (as the independent variable), according to ring type (as in Table 1 and Figure 4)

\begin{tabular}{|c|c|c|c|c|c|c|}
\hline $\begin{array}{l}\text { Structure } \\
\text { Type }\end{array}$ & Ring Type ${ }^{(c)}$ & $\begin{array}{l}\text { Place on Map } \\
\text { of Figure } 4^{(\mathrm{e})}\end{array}$ & No. of Points & $R^{2(\mathrm{~d})}$ & $\begin{array}{l}\text { Slope } \\
\quad S\end{array}$ & $\begin{array}{c}\text { Intercept } \\
t\end{array}$ \\
\hline \multicolumn{7}{|c|}{ Positive Slopes } \\
\hline Cata & $g$ & South-West & 6 & 0.996 & 0.341 & 0.072 \\
\hline Peri & $i, k$ & South-West & 8 & 0.992 & 0.498 & -0.179 \\
\hline Cata + Peri & $g, i, k$ & South-West & 14 & 0.951 & 0.395 & -0.015 \\
\hline Peri & $e$ & Centre & 20 & 0.924 & 0.522 & -0.769 \\
\hline Cata & $c$ & Centre & 25 & 0.968 & 0.293 & -0.065 \\
\hline Peri & $f$ & Centre & 9 & 0.706 & 0.382 & -0.135 \\
\hline Cata & $a$ & Centre & 18 & 0.854 & 0.139 & 0.439 \\
\hline \multicolumn{7}{|c|}{ Negative Slopes } \\
\hline Peri & $a^{\prime}$ & North-East & 6 & 0.979 & -0.804 & 5.408 \\
\hline Cata + Peri & $a^{\prime}$ & North-East & 30 & 0.868 & -0.274 & 2.568 \\
\hline Cata + Peri & $d^{\prime}$ & North-East & 11 & 0.978 & -1.441 & 7.858 \\
\hline Cata + Peri & $d$ & North-East & 5 & 0.996 & -0.753 & 4.805 \\
\hline
\end{tabular}

(a) There are no significant correlations for types $b$ and $d^{\prime \prime}$.

(b) The correlations have the form: Ring Current $=s \times($ Ring Partition $)+t$

(c) Ring Types are according to the geometrical classifications described in Table 1 and depicted in Figure 2.

(d) $R^{2}$ is the square of the respective correlation-coefficient.

(e) "Place on Map of Figure 4" refers to the region of Figure 4 in which the plotted points being considered actually occur.
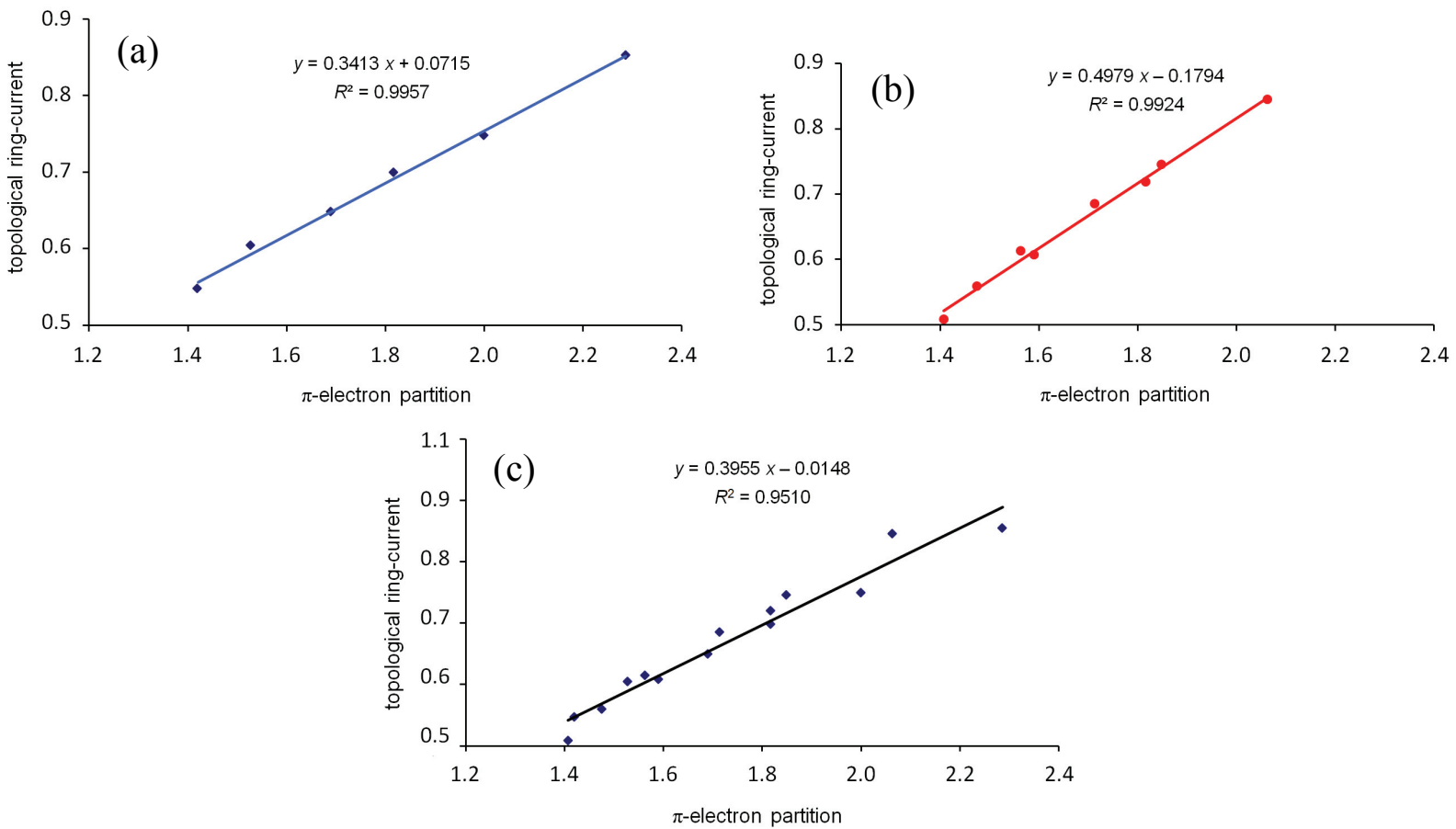

Figure 5. Linear correlations between topological $\pi$-electron ring-currents and $\pi$-electron partitions for ring types $g$ (a), $i$ and $k$ (b), and all three of these ring types combined (c).

rather than an aromatic character. Both for anthracene and phenanthrene, Clar structures ${ }^{27,58}$ also assign a lower "sextet character" to the central rings. This aspect agrees with the fact that the slope of correlations between topological $\pi$-electron ring-currents and $\pi$-electron partitions for the highest values of the latter parameter become negative.
In order to investigate how ring types affect the local aromaticity we now consider a third criterion of local aromaticity in polycyclic benzenoids - the sixcentre delocalisation-indices, denoted as $\Delta_{6}$. These may also be regarded as a measure of "local aromaticity" and were recently introduced by Mandado et al. ${ }^{36,68}$ Table 5 compares the previous two local-aromaticity parameters 
Table 5. Three local-aromaticity indices. The numbers that are here denoted "M\#", identifying the compounds under discussion, are replicated directly from Mandado et $_{\text {al. }}{ }^{36}$

\begin{tabular}{|c|c|c|c|c|c|c|c|c|}
\hline Compound & $\mathrm{M} \#$ & $K$ & Ring & Partition & $100 \times \Delta_{6}$ & Ring Current & Ring Type & Structure \\
\hline C1 & 2 & 3 & $\mathrm{AA}$ & 5.00 & 2.63 & 1.09 & $a$ & \\
\hline \multirow[t]{2}{*}{$\mathrm{C} 2$} & 3 & 4 & $\mathrm{AA}$ & 4.75 & 1.99 & 1.09 & $a$ & \\
\hline & & & B & 4.50 & 1.89 & 1.28 & $d^{\prime \prime}$ & \\
\hline \multirow[t]{2}{*}{$\mathrm{C} 3$} & 8 & 5 & $\mathrm{AA}$ & 5.20 & 3.14 & 1.13 & $a^{\prime}$ & \\
\hline & & & $\mathrm{B}$ & 3.60 & 1.19 & 0.975 & $c$ & \\
\hline \multirow[t]{2}{*}{$\mathrm{C} 4$} & 4 & 5 & $\mathrm{AA}$ & 4.60 & 1.72 & 1.07 & $a$ & \\
\hline & & & $\mathrm{BB}$ & 4.40 & 1.59 & 1.31 & $d^{\prime \prime}$ & \\
\hline \multirow[t]{4}{*}{ C5 } & 12 & 7 & A & 4.86 & 2.22 & 1.12 & $a$ & \\
\hline & & & B & 4.57 & 2.05 & 1.27 & $d^{\prime}$ & \\
\hline & & & $\mathrm{C}$ & 3.29 & 0.86 & 0.891 & $c$ & \\
\hline & & & $\mathrm{D}$ & 5.29 & 3.32 & 1.12 & $a^{\prime}$ & \\
\hline \multirow[t]{2}{*}{ C6 } & 10 & 8 & $\mathrm{AA}$ & 5.13 & 2.98 & 1.15 & $a^{\prime}$ & \\
\hline & & & $\mathrm{BB}$ & 3.88 & 1.49 & 1.07 & $c$ & \\
\hline \multirow[t]{2}{*}{$\mathrm{C} 7$} & 11 & 9 & AAA & 5.33 & 3.47 & 1.11 & $a^{\prime}$ & \\
\hline & & & B & 2.00 & 0.51 & 0.747 & $g$ & \\
\hline \multirow[t]{3}{*}{$\mathrm{C8}$} & 5 & 6 & $\mathrm{AA}$ & 4.50 & 1.59 & 1.06 & $a$ & \\
\hline & & & $\mathrm{BB}$ & 4.33 & 1.43 & 1.30 & $d^{\prime \prime}$ & \\
\hline & & & $\mathrm{C}$ & 4.33 & 1.41 & 1.35 & $d^{\prime \prime}$ & \\
\hline \multirow[t]{5}{*}{ C9 } & 17 & 9 & A & 4.67 & 1.84 & 1.09 & $a$ & \\
\hline & & & B & 4.44 & 1.69 & 1.32 & $d^{\prime \prime}$ & \\
\hline & & & $\mathrm{C}$ & 4.44 & 1.66 & 1.35 & $d^{\prime \prime}$ & \\
\hline & & & D & 3.11 & 0.73 & 0.847 & $c$ & \\
\hline & & & $\mathrm{E}$ & 5.33 & 3.38 & 1.11 & $a^{\prime}$ & \\
\hline \multirow[t]{3}{*}{$\mathrm{C} 10$} & 18 & 10 & $\mathrm{AA}$ & 4.90 & 2.32 & 1.11 & $a$ & \\
\hline & & & BB & 4.60 & 2.07 & 1.23 & $d^{\prime}$ & \\
\hline & & & $\mathrm{C}$ & 3.00 & 0.63 & 0.784 & $c$ & \\
\hline \multirow[t]{5}{*}{ C11 } & 21 & 11 & A & 4.82 & 2.14 & 1.12 & $a$ & \\
\hline & & & B & 4.55 & 2.01 & 1.30 & $d^{\prime}$ & \\
\hline & & & $\mathrm{C}$ & 3.55 & 1.09 & 0.993 & $c$ & \\
\hline & & & D & 4.00 & 1.61 & 1.08 & $c$ & \\
\hline & & & $\mathrm{E}$ & 5.09 & 2.90 & 1.15 & $a^{\prime}$ & \\
\hline \multirow[t]{3}{*}{$\mathrm{C} 12$} & 14 & 12 & $\mathrm{AA}$ & 5.25 & 3.24 & 1.14 & $a^{\prime}$ & \\
\hline & & & BB & 3.42 & 0.97 & 0.943 & $c$ & \\
\hline & & & $\mathrm{C}$ & 4.67 & 2.33 & 1.29 & $d$ & \\
\hline \multirow[t]{3}{*}{$\mathrm{C} 12$} & 15 & 12 & AA & 5.25 & 3.24 & 1.14 & $a^{\prime}$ & \\
\hline & & & BB & 3.42 & 0.97 & 0.944 & $c$ & \\
\hline & & & $\mathrm{C}$ & 4.67 & 2.30 & 1.29 & $d$ & \\
\hline \multirow[t]{3}{*}{$\mathrm{C} 13$} & 20 & 13 & $\mathrm{AA}$ & 5.15 & 3.03 & 1.16 & $a^{\prime}$ & \\
\hline & & & BB & 3.77 & 1.39 & 1.06 & $c$ & \\
\hline & & & $\mathrm{C}$ & 4.15 & 1.86 & 1.15 & $c$ & \\
\hline \multirow[t]{4}{*}{ C14 } & 19 & 13 & A & 4.92 & 2.30 & 1.12 & $a$ & \\
\hline & & & B & 4.62 & 2.19 & 1.21 & $d^{\prime}$ & \\
\hline & & & $\mathrm{C}$ & 1.69 & 0.37 & 0.648 & $g$ & \\
\hline & & & DD & 5.39 & 3.57 & 1.08 & $a^{\prime}$ & \\
\hline
\end{tabular}


Table 5. Continued

\begin{tabular}{|c|c|c|c|c|c|c|c|c|}
\hline Compound & $\mathrm{M} \#$ & $K$ & Ring & Partition & $100 \times \Delta_{6}$ & Ring Current & Ring Type & Structure \\
\hline \multirow[t]{3}{*}{ C16 } & 6 & 7 & $\mathrm{AA}$ & 4.43 & 1.52 & 1.05 & $a$ & \\
\hline & & & $\mathrm{BB}$ & 4.29 & 1.35 & 1.29 & $d^{\prime \prime}$ & \\
\hline & & & $\mathrm{CC}$ & 4.29 & 1.31 & 1.35 & $d^{\prime \prime}$ & \\
\hline \multirow[t]{2}{*}{ P1 } & 9 & 6 & $\mathrm{AA}$ & 4.67 & 2.43 & 1.33 & $b$ & \\
\hline & & & $\mathrm{BB}$ & 3.33 & 1.23 & 0.964 & $e$ & \\
\hline \multirow[t]{5}{*}{ P3 } & 13 & 9 & $\mathrm{~A}$ & 5.00 & 2.64 & 1.21 & $a^{\prime}$ & \\
\hline & & & B & 3.67 & 1.29 & 1.29 & $f$ & \\
\hline & & & $\mathrm{C}$ & 3.11 & 0.95 & 0.848 & $e$ & \\
\hline & & & $\mathrm{D}$ & 4.67 & 2.40 & 1.30 & $b$ & \\
\hline & & & $\mathrm{E}$ & 3.56 & 1.56 & 1.08 & $e$ & \\
\hline \multirow[t]{4}{*}{ P4 } & 16 & 11 & A & 5.36 & 3.50 & 1.10 & $a^{\prime \prime}$ & \\
\hline & & & $\mathrm{B}$ & 1.82 & 0.54 & 0.719 & $i$ & \\
\hline & & & $\mathrm{CC}$ & 4.73 & 2.65 & 1.29 & $b$ & \\
\hline & & & $\mathrm{D}$ & 3.36 & 1.21 & 0.987 & $e$ & \\
\hline \multirow[t]{3}{*}{ P6 } & 23 & 10 & $\mathrm{AA}$ & 4.60 & 2.15 & 1.34 & $b$ & \\
\hline & & & $\mathrm{BB}$ & 3.30 & 1.31 & 1.30 & $h$ & \\
\hline & & & $\mathrm{CC}$ & 3.10 & 0.97 & 0.854 & $e$ & \\
\hline \multirow[t]{6}{*}{ P17 } & 25 & 17 & $\mathrm{~A}$ & 5.06 & 2.71 & 1.20 & $a^{\prime}$ & \\
\hline & & & $\mathrm{B}$ & 3.65 & 1.38 & 1.23 & $f$ & \\
\hline & & & $\mathrm{C}$ & 3.59 & 1.52 & 1.09 & $e$ & \\
\hline & & & $\mathrm{D}$ & 4.71 & 2.57 & 1.26 & $b$ & \\
\hline & & & E & 1.59 & 0.41 & 0.606 & $i$ & \\
\hline & & & F & 5.41 & 3.58 & 1.06 & $a^{\prime \prime}$ & \\
\hline \multirow[t]{3}{*}{ P18 } & 24 & 20 & AA & 5.35 & 3.48 & 1.11 & $a^{\prime \prime}$ & \\
\hline & & & BB & 1.85 & 0.53 & 0.745 & $i$ & \\
\hline & & & $\mathrm{CC}$ & 4.80 & 2.90 & 1.27 & $b$ & \\
\hline
\end{tabular}

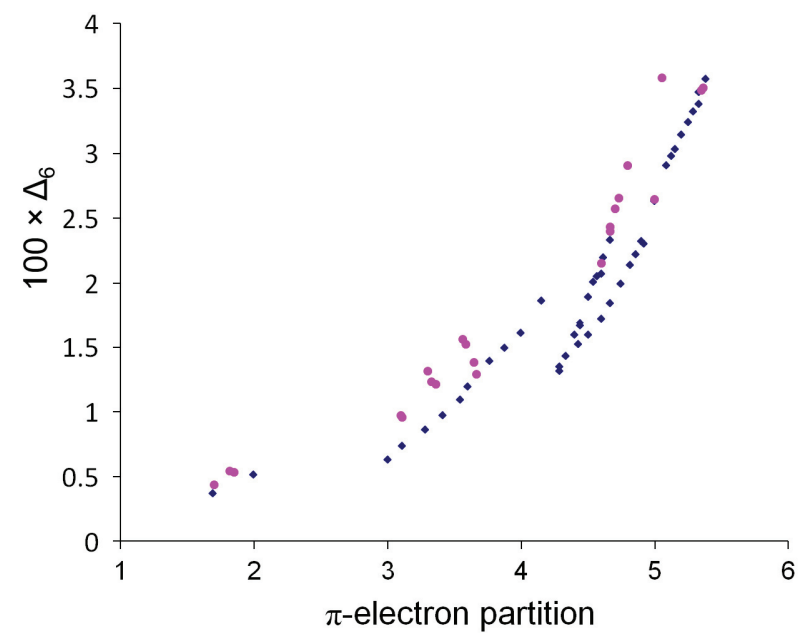

Figure 6. Plot of $\Delta_{6}$-values (from Ref. 36) along the vertical axis $v s$. $\pi$-electron partitions, ${ }^{33,34}$ on the horizontal axis. The blue and the purple colours indicate catafusenes and perifusenes, respectively.

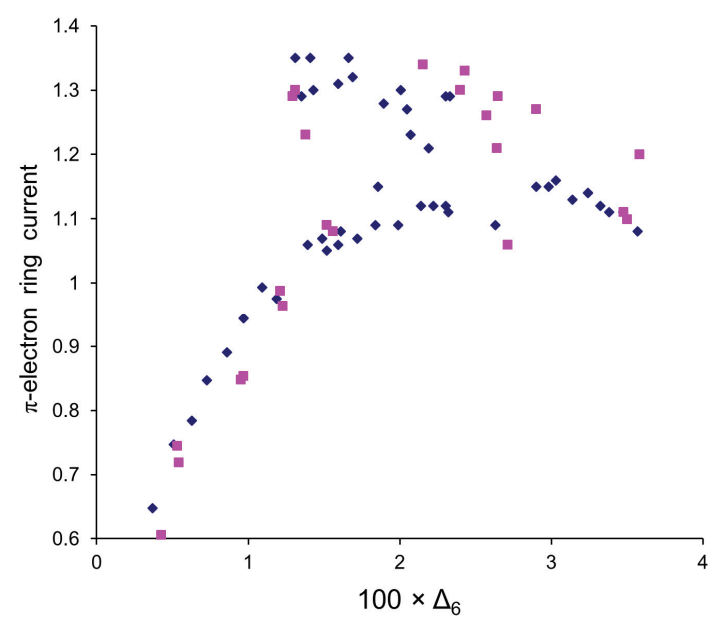

Figure 7. Plot of topological $\pi$-electron ring-currents (from Ref. 35) along the vertical axis vs. $\Delta_{6}$-values (from Ref. 36), along the horizontal axis. The blue and the purple colours indicate catafusenes and perifusenes, respectively. 
(topological $\pi$-electron ring-currents and $\pi$-electron partitions), with this third one, $\Delta_{6}$, by means of the data provided in Ref. 36.

In connexion with Table 5 , it should be noted that two isoarithmic catafusenes were listed separately in the paper by Mandado et al., ${ }^{36}$ as items $\mathbf{1 4}$ and $\mathbf{1 5}$ - but they both here correspond to the structure that we have labelled $^{34}$ as $\mathbf{C 1 2}$.

As seen in Figure 6, the plot of a convenient multiple (100) of $\Delta_{6} v s$. $\pi$-electron partitions is as fragmented as the plot of $\pi$-electron ring-currents $v s$. $\pi$-electron partitions shown in Figure 4, but it has only positive slopes, indicating that these two criteria are congruent, at least to some extent. One might, therefore, construct several distinct local (fragmented) linear-correlations between these parameters according to various ring types, conserving the classification of such ring types from the previous tables.

An intriguing aspect of Figure $7-\pi$-electron ringcurrents $v s$. a convenient multiple (100) of the $\Delta_{6}$-values - is that it qualitatively mirrors the plot of Figure 4 (of $\pi$-electron ring-currents $v s$. $\pi$-electron partitions). The two are not dissimilar in that there is an approximate positive correlation up to ring-current values of about 1.2 - or, rather, two, separate, parallel ones: one for ring currents up to values of about 0.8 and another for ringcurrent values between about 0.8 and 1.2. Again, however - as in Figure $4-$ for the highest $\Delta_{6}$-values, the slope of the correlation with topological $\pi$-electron ringcurrents becomes negative for the higher ring-current and $\Delta_{6}$-values.

\section{CONCLUSIONS}

Comparisons of Figures 4 and 6 on the one hand, and of Figures 4 and 7 on the other, inevitably invite the general conclusion that - despite its superficially intuitive appeal - the "ring-current" index is out of step with the other two indices considered here $-\pi$-electron partitions and $\Delta_{6}$-values - as an index of what might be regarded as "local aromaticity". This conclusion agrees with the idea that aromaticity is a multi-dimensional and scaledependent phenomenon ${ }^{12-19}$ - but see Ref. 15 for the opposite viewpoint.

It should, though, be observed that the topological $\pi$-electron ring-currents for most (but not all) ring types are congruent with other indices that are frequently suggested as encapsulating the extent of such "local aromaticity". In particular, the analysis presented here shows that magnetic criteria disagree with other local aromaticity criteria only when discussing fragments of polycyclic condensed aromatic hydrocarbons containing linearly-condensed terminal and next-to-terminal benzenoid rings. Finally, it may be noted in passing that recent studies have also shown a remarkable concord- ance between topological $\pi$-electron ring-currents and energy-effect values ${ }^{69,70}$ in the central ring of perylenelike structures ${ }^{71}$ and in the five-membered ring of conjugated systems related to fluoranthene. ${ }^{54}$

Note aded in proof. Since the submission of this manuscript, the following papers relevant to it have appeared: (a) a review on $\pi$-electron partitions; ${ }^{72}$ (b) two papers pertinent to our discussion of anthracene and phenanthrene, ${ }^{73,74}$ (c) further developments ${ }^{75}$ on the topological aspects of the aufbau process, dealt with in Refs. 28-32.

\section{REFERENCES}

1. C. W. Haigh and R. B. Mallion, Ring Current Theories in Nuclear Magnetic Resonance, in: Progress in Nuclear Magnetic Resonance Spectroscopy, J. W. Emsley, J. Feeney, and L. H. Sutcliffe (Eds), Pergamon Press, Oxford, 1979/1980, Vol. 13, pp. 303344.

2. P. Lazzeretti, Ring Currents, in: Progress in Nuclear Magnetic Resonance Spectroscopy J. W. Emsley, J. Feeney, and L. H. Sutcliffe (Eds), Elsevier, Amsterdam, 2000, Vol. 36, pp. 1-88.

3. L. Salem, Molecular Orbital Theory of Conjugated Systems, W. A. Benjamin, New York, 1966, Chapter 9.

4. J. A. N. F. Gomes and R. B. Mallion, The Concept of Ring Currents, in: D. H. Rouvray (Ed), Concepts in Chemistry: A Contemporary Challenge, Research Studies Press, Taunton, Somerset (England, United Kingdom), 1997, pp. 205-253.

5. J. A. Elvidge and L. M. Jackman, J. Chem. Soc. (1961), pp. 859 866.

6. J. A. Elvidge, Chem. Commun. (1965), pp. 160-161.

7. R. J. Abraham and W. A. Thomas, J. Chem. Soc. B (1966), pp 127-131

8. J. A. N. F. Gomes and R. B. Mallion, Chem. Rev. 101 (2001) 1349-1383.

9. J.-F. Labarre and F. Crasnier, Fort. Chem. Forsch. (Topics Current Chem.) 24 (1971) 33-54.

10. A. T. Balaban, Pure Appl. Chem. 52 (1980) 1409-1429.

11. R. B. Mallion, Pure Appl. Chem. 52 (1980) 1541-1548.

12. M. K. Cyrański, T. M. Krygowski, A. R. Katritzky, and P. v. R. Schleyer, J. Org. Chem. 2002, 67 1333-1338.

13. P. Bultinck, S. Fias, and R. Ponec, Chem. Eur. J. 12 (2006) 8813-8818

14. S. Fias, S. Van Damme, and P. Bultinck, J. Comput. Chem. 29 (2007) 358-366

15. S. Fias, P. W. Fowler, J. L. Delgado, U. Hahn, and P. Bultinck, Chem. Eur. J. 14 (2008) 3093-3099.

16. A. Ciesielski, T. M. Krygowski, M. K. Cyrański, A Dobrowolski, A. T. Balaban, and P. Bultinck, J. Chem. Inf. Model. 49 (2009) 369-376.

17. R. Ponec, S. Fias, S. van Damme, P. Bultinck, I. Gutman, and S. Stanković, Coll. Czech. Chem. Commun. 74 (2009) 147-166.

18. S. Fias, S. Van Damme, and P. Bultinck, J. Comput. Chem. 31 (2010) 2286-2293

19. M. Mandado, Theoret. Chem. Accounts 126 (2010) 339-349.

20. A. T. Balaban, D. C. Oniciu, and A. R. Katritzky, Chem. Rev. 104 (2004) 2777-2812.

21. A. T. Balaban, Aromaticity of Six-membered Rings with one Heteroatom, in: T. M. Krygowski and M. K. Cyrański, (Eds), Aromaticity in Heterocyclic Compounds, Springer, New York, 2009, pp 203-246.

22. A. T. Balaban, Monocyclic Hetarenes with $\pi$-Electron Aromatic Sextet, in: A. R. Katritzky (Ed.), Advances in Heterocyclic Chemistry, Elsevier, Amsterdam, 2010, Vol. 99, pp 69-105. 
23. R. B. King, Chem. Rev. 101 (2001) 1119-1152.

24. Z. Chen and R. B. King, Chem. Rev. 105 (2005) 3613-3642.

25. C. A. Coulson and C. W. Haigh, Tetrahedron, 19 (1963) 527544.

26. C. W. Haigh and R. B. Mallion, Mol. Phys. 22 (1971) 955-970.

27. E. Clar, The Aromatic Sextet, Wiley: London, 1972

28. R. B. Mallion and D. H. Rouvray, Mol. Phys. 36 (1978) 125-128.

29. R. B. Mallion and D. H. Rouvray, Studia Scientiarum Mathematicarum Hungarica 13 (1978) 229-243.

30. R. B. Mallion, Some Chemical Applications of the Eigenvalues and Eigenvectors of Certain Finite, Planar Graphs, in: Applications of Combinatorics, R. J. Wilson (Ed.), Shiva Publishing Ltd., Nantwich, Cheshire (England, United Kingdom), 1982, Chapter 7, pp. 87-117.

31. R. B. Mallion, Croat. Chem. Acta 56 (1983) 477-490.

32. R. B. Mallion, The Topological Nature of the Aufbau Process and of Quantities Calculated via Simple Molecular-Orbital Theory, in: Mathematical Methods and Modelling for Students of Chemistry and Biology: Proceedings of the Conference "Mathematical Methods in Chemistry", Split, Croatia, September 22-24, 2007, A. Graovac, I. Gutman, and D. Vukičević (Eds.). Hum naklada d.o.o., Zagreb, 2009, pp. 55-86.

33. M. Randić and A. T. Balaban, Int. J. Quant. Chem. 108 (2008) 865-897.

34. A. T. Balaban and M. Randić, Int. J. Quant. Chem. 108 (2008) 898-926.; Erratum, ibid. III (2011) 3643-3646.

35. R. B. Mallion, Croat. Chem. Acta 81 (2008) 227-246.

36. M. Mandado, P. Bultinck, M. J. González-Moa, and R. A. Mosquera, Chem. Phys. Lett. 433 (2006) 5-9.

37. M. Randić, Chem. Rev. 103 (2003) 3449-3636.

38. M. Randić, J. Chem. Inf. Comput. Sci. 44 (2004) 365-372.

39. M. Randić and A. T. Balaban, Polycyclic Arom. Comp. 24 (2004) 173-193.

40. A. T. Balaban and M. Randić, J. Chem. Inf. Comput. Sci. 44 (2004) 50-59.

41. A. T. Balaban and M. Randić, New J. Chem. 28 (2004) 800-806.

42. D. Vukičević, M. Randić, and A. T. Balaban, J. Math. Chem. 36 (2004) 271-279.

43. A. T. Balaban and M. Randić, J. Chem. Inf. Comput. Sci. 44 (2004) 1701-1707.

44. A. T. Balaban and M. Randić, J. Math. Chem. 37 (2005) 443-453.

45. M. Randić and A. T. Balaban, J. Chem. Inf. Comput. Sci. 46 (2006) 57-64.

46. A. T. Balaban and M. Randić, New J. Chem. 32 (2008) 1071-1078.

47. A. T. Balaban, M. Pompe, and M. Randić, J. Phys. Chem A 112 (2008) 4148-4157.

48. A. T. Balaban, J. Đurđević, I. Gutman, S. Jeremić, and S. Radenković, J. Phys. Chem. A 114 (2010) 5870-5877.

49. C. A. Coulson, B O'Leary, and R. B. Mallion, Hückel Theory For Organic Chemists, Academic Press, London,1978.

50. K. H. Yates, Hückel Molecular Orbital Theory, Academic Press, New York, 1978

51. F. London, J. Phys. Radium (7érie) 8 (1937) 397-409.
52. J. A. Pople, Mol. Phys. 1 (1958) 175-180.

53. R. McWeeny, Mol. Phys. 1 (1958) 311-321.

54. A. T. Balaban, T. K. Dickens, I. Gutman, and R. B. Mallion, Croat. Chem. Acta 83 (2010) 209-215.

55. D. Janežič, A. Miličević, S. Nikolić, and N. Trinajstić, Graph Theoretical Matrices in Chemistry. Mathematical Chemistry Monographs, Faculty of Science, University of Kragujevac (Serbia), 2007.

56. R. B. Mallion, Mol. Phys. 25 (1973) 1415-1432.

57. R. B. Mallion, Proc. Royal Soc. (London) Ser. A 341 (1974/1975) 429-449.

58. I. Gutman and S. J. Cyvin, Introduction to the Theory of Benzenoid Hydrocarbons, Springer-Verlag: Berlin (West), 1989.

59. A. T. Balaban and F. Harary, Tetrahredron 24 (1968) 2505-2516.

60. I. Gutman, R. B. Mallion, and J. W. Essam, Mol. Phys. 50 (1983) 859-877.

61. A. T. Balaban and I. Tomescu, MATCH Commun. Math. Comput. Chem. 14 (1983) 155-182.

62. A. T. Balaban, MATCH Commun. Math. Comput. Chem. 24 (1989) 29-38.

63. T. M. Krygowski and M. K. Cyrański, Chem. Rev. 101 (2001) 1385-1419.

64. C. W. Haigh and R. B. Mallion, J. Chem. Phys. 76 (1982) $4063-$ 4066.

65. P. v. R. Schleyer and H. Jiao, Pure Appl. Chem. 68 (1996) 209218.

66. P. v. R. Schleyer, C. Maerker, A. Dransfeld, H. Jiao, and N. J. R. van Eikema Hommes, J. Am. Chem. Soc. 118 (1996) 6317-6318.

67. Z. Chen, C. S. Wannere, C. Corminboeuf, R. Puchta, and P. v. R. Schleyer, Chem. Rev. 105 (2005) 3842-3888.

68. M. Mandado, M. J. Gonzáles Moa, and R. A. Mosquera, Aromaticity: Exploring Basic Chemical Concepts with the Quantum Theory of Atoms in Molecules, Nova Science Publishers, Hauppauge, New York, 2008.

69. I. Gutman, Monatsh. Chem. 136 (2005) 1055-1069.

70. I. Gutman, Mathematical Modeling of Chemical Phenomena, in: Mathematical Methods and Modelling for Students of Chemistry and Biology: Proceedings of the Conference "Mathematical Methods in Chemistry", Split, Croatia, September 22-24, 2007, A. Graovac, I. Gutman, and D. Vukičević (Eds.). Hum naklada d.o.o., Zagreb, 2009, pp. 13-27.

71. T. K. Dickens and R. B. Mallion, J. Phys. Chem. A 115 (2011) 331-356.

72. A. T. Balaban and M. Randić, Structural Approach to Aromaticity and Local Aromaticity in Conjugated Polycyclic Systems, in: Carbon Bonding and Structures: Advances in Physics and Chemistry. Carbon Materials: Chemistry and Physics 5, M. V. Putz (Ed.), Springer Science+Business Media B. V., 2011, pp. 159-204.

73. P. v. R. Schleyer, M. Manoharan, H. Jiao, and F. Stahl, Org. Lett. 3 (2001) 3643-3646

74. S. Sakai and Y. Kita, J. Phys. Org. Chem. (2012).

75. A. Ceulemans, E. Lijnen, P. W. Fowler, R. B. Mallion, and T. Pisanski, Proc. R. Soc. A (2011). 